\title{
Local and global processing: The role of sparsity
}

\author{
MARYANNE MARTIN \\ University of Oxford, Oxford OX13UD, England
}

\begin{abstract}
It has recently been proposed that global processing precedes local processing of a visual scene even when the local and the global aspects are similar in nature (e.g., both alphabetic). The two types of processing were compared here in four different ways, for stimuli with many and with few local elements (i.e., differing sparsities). These methods consisted of assessing naming latency, intrastimulus Stroop-like interference, intermodality Stroop-like interference, and phenomenal judgment. The results of four experiments were consistent in demonstrating global processing priority for manyelement stimuli but local processing priority for fewelement stimuli.
\end{abstract}

A question that has recently received considerable investigation is that of the extent to which human information processing may be analyzed in terms of input-driven and concept-driven mechanisms. In activities such as reading (Levy, 1977), picture recognition (Palmer, 1975a, 1975b), speech perception (MarslenWilson \& Welsh, 1978), and problem solving (Eisenstadt \& Kareev, 1975), these mechanisms have usually been defined with respect to physical and semantic levels of analysis. A purely input-driven model would postulate the existence of a series of stages of analysis from sensory representation to meaning, the output of each stage of analysis forming the input to the next. Constraints derived from the higher levels have no control over decisions at a lower level. Concept-driven mechanisms, on the other hand, exert important influences of this type via high-level constraints on possible interpretations operating at early stages of processing.

Physical and semantic elements of information often inhere in either local or in global aspects of the stimulus (e.g., the positions of individual letters of a written word can be specified separately, while its meaning is derived from all of the letters). Thus it is possible that corresponding to the ordering in which input-driven and concept-driven processes occur in perception, there exists a related ordering of processing of local and global stimulus aspects. Specifically, several theorists have subscribed to the recent proposal by Navon (1977) that processing of global characteristics of a visual stimulus precedes processing of local characteristics (e.g., Broadbent, 1977; Broadbent \& Broadbent, in press; Fox, 1978; Lupker, 1979; Norman \& Bobrow,

The author wishes to thank Czesia James for testing the subjects in Experiment 1 and Nancy Chenier for testing the subjects in Experiments 2, 3, and 4. The research was supported by the British Science Research Council. Requests for reprints should be addressed to Maryanne Martin, Department of Experimental Psychology, University of Oxford, South Parks Road, Oxford OX1 3UD, England.
Note 1). Similar proposals have also been made by other theorists (e.g., Bouma, 1971; Eriksen \& Schultz, 1978; Lockhead, 1972; Monahan \& Lockhead, 1977; Neisser, 1976). This view is clearly compatible with the Gestalt theory that perception of a part of a stimulus is determined by perception of the whole, rather than the reverse (e.g., Wertheimer, 1944). It may be contrasted with feature-accumulation models that (as in the pattern recognition model of Selfridge, 1959) view processing as proceeding from the local to the global (e.g., Gibson, 1969; Lindsay \& Norman, 1972; Rumelhart \& Siple, 1974; Treisman \& Gelade, in press; Treisman, Sykes, \& Gelade, 1977). Pomerantz and Sager (1975) have reported the occurrence of slight local, rather than global, precedence even when discrimination of the global element was easier than that of the local element. The experiments to be reported here, on the other hand, indicate that neither class of model holds universally. Rather, it appears that either local or global characteristics may be extracted earlier, as proposed also by Kinchla and Wolfe (1979). For the specific variable manipulated here, it was found that the order of processing of global and of local aspects depended upon stimulus sparsity (i.e., upon whether the stimulus had many or few local elements).

The question of local and global precedence may also be related to recent theoretical treatments (Estes, 1975; Johnston, 1978; McClelland \& Johnston, 1977) of the word superiority effect. This refers to the finding that a letter in a familiar word may be perceived more accurately (Reicher, 1969; Wheeler, 1970) or more rapidly (Krueger, 1970) than the same letter in isolation or in a string of unrelated letters. The effect can be vitiated, however, by manipulating redundancy (Massaro, 1973) or visual angle (Purcell, Stanovitch, \& Spector, 1978). A problem in the interpretation of the word superiority effect is that the local-global nature of the letter-word distinction is confounded with other factors such as degree of internal redundancy and of 
richness of encoding. This problem does not arise in the present experiments, for which local and global elements were made directly comparable.

The experiments to be reported are similar in several respects to those of Navon (1977). To prevent differences between local and global elements arising from extraneous factors, Navon used as stimuli single large letters (global aspects) that were composed of several small letters (local aspects) of a particular type. Similar stimuli have been used also by Kinchla $(1974,1977)$ and Martin (1978a, in press). Navon (1977) found that if the subject's attention was directed toward the local aspects, conflicting global aspects slowed down perception of them, whereas perception of global aspects was not impaired by conflicting local aspects. Navon concluded that global analysis precedes local analysis, making it possible to respond on the basis of global aspects alone, but not to respond on the basis of local aspects without suffering interference from the more rapidly analyzed global information.

The above interpretation has two distinct components, both open to further empirical investigation. The first is the postulate that global processing precedes local processing. The second is that when two conflicting types of information are processed, perception of the more slowly available type is impaired by the presence of the more rapidly available type, but not the reverse. In the Stroop (1935) paradigm, this postulate has been advanced as a "race" explanation for observed patterns of interference (Cohen \& Martin, 1975; Martin, 1978b; Morton \& Chambers, 1973). It is possible logically for both, either, or neither of these two propositions to hold in general. A series of experiments was carried out to test them empirically.

\section{EXPERIMENT 1}

On each trial in Experiment 1, subjects were shown a global letter composed of several examples of a smaller, local letter. The sparsity of each stimulus was varied by having each global aspect comprise either many or few local ones. The subject's task was to report in each case the name of either the local or the global aspect (as instructed) as rapidly as possible.

\section{Method}

Subjects. The subjects were 16 right-handed members of the Oxford subject panel, aged between 18 and 30 years. Eight were female and eight were male. All had normal or fully corrected vision. They were tested individually.

Stimuli and Apparatus. The two sets of nine different patterns incorporated into the stimuli of all four experiments are shown in Figures 1 and 2 (many and few local elements, respectively). As can be seen, each of the patterns consists of a global shape $(\mathrm{H}, \mathrm{S}$, or $\mathrm{O}$ ) made up of local shapes (again $\mathrm{H}$, $S$, or $O$ ), with all shapes having the same height-to-width ratio. This experiment used eight of the nine types of pattern, excluding that with both local and global $O$ shape.

The stimuli were presented as black patterns on white cards in a Cambridge three-field tachistoscope. Fach stimulus was preceded by a central fixation point and followed by a visual random noise mask. The cards were $10.2 \times 15.2 \mathrm{~cm}$. The global
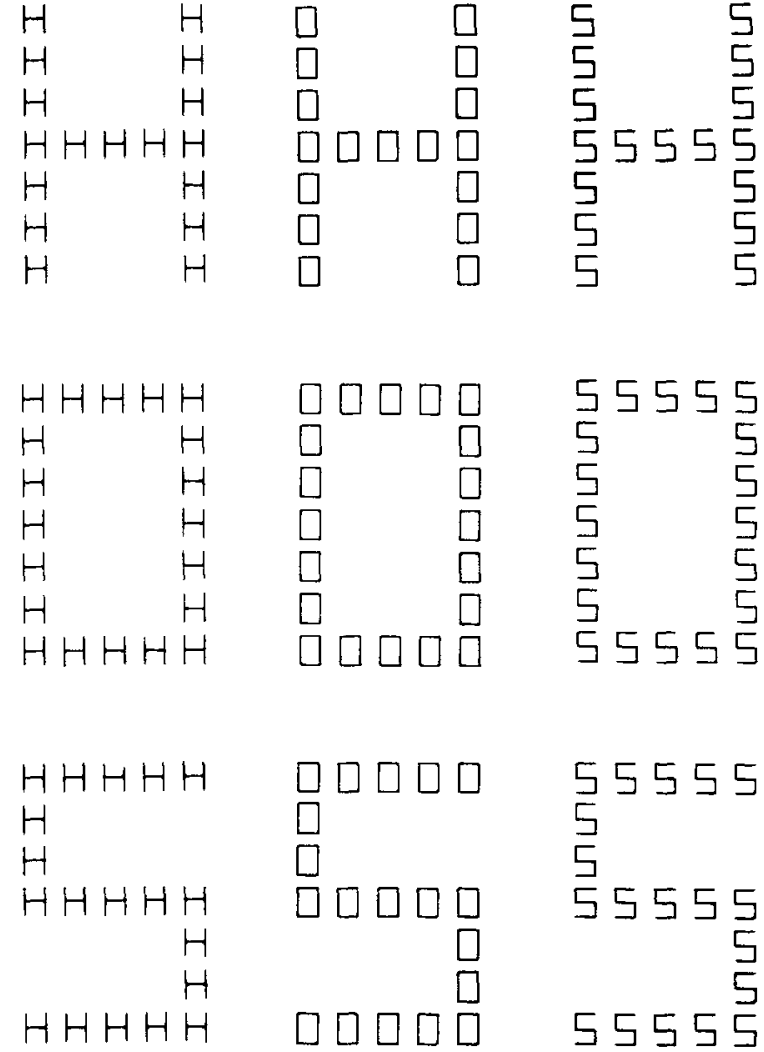

Figure 1. Many-element stimulus pattems.
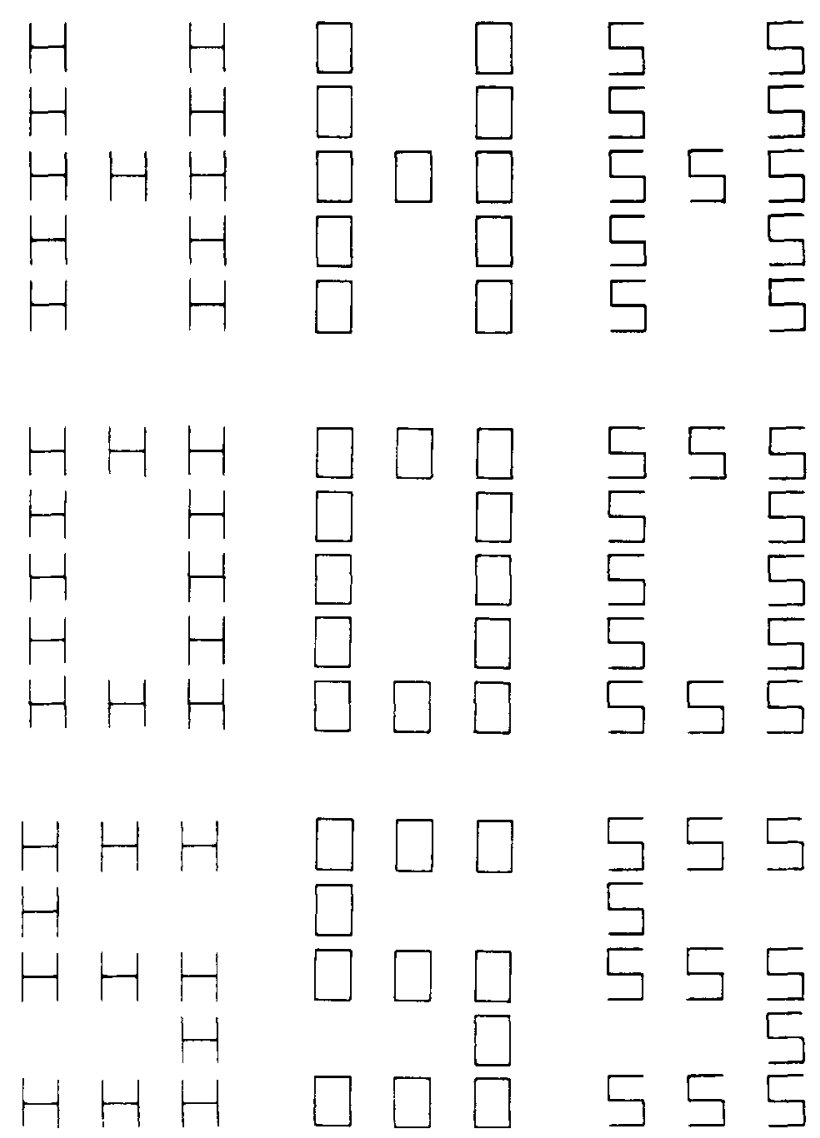

Figure 2. Few-element stimulus patterns. 
letter on each card was $2.5 \times 3.6 \mathrm{~cm}$; the local letters were $.30 \times .43 \mathrm{~cm}$ for the "many" case and $.45 \times .60 \mathrm{~cm}$ for the "few" case. Each card had 1 of the 16 stimulus patterns drawn in one of the four quadrants of that card, immediately adjacent to the card's central and vertical axes. The viewing distance was $50.8 \mathrm{~cm}$, and thus the global shape subtended $2.8 \mathrm{deg}$ to the left or right of center and $4.1 \mathrm{deg}$ above or below it.

Procedure. On each trial an auditory signal warned the subject to look at the central fixation point. This was followed $3 \mathrm{sec}$ later by the stimulus, which appeared in each of the quadrants with equal frequency. The stimulus appeared for $100 \mathrm{msec}$ and was followed immediately by the mask for $1 \mathrm{sec}$. The subject was instructed beforehand to attempt to identify either the global or the local shape. There were 288 experimental trials and 24 practice trials. The trials were divided into four blocks of 72 trials each. Two of the blocks contained stimuli with many local elements, and the remaining two blocks contained stimuli with few local elements. Report of the global shape was required in one block and report of the local shape in the other, for both pairs of blocks. The order of completing the four blocks was counterbalanced across subjects. When subjects were instructed to report the global shape, they were only presented the six stimulus patterns with global $\mathrm{H}$ or $\mathrm{S}$ (and instructed to report either $\mathbf{H}$ or $\mathbf{S}$ ); similarly, for local shape reports, only the six stimulus patterns with local shape $H$ or $S$ were used (and report was again $\mathrm{H}$ or $\mathrm{S}$ ). Depending on whether the name of the unattended shape was the same as that to be reported (e.g., both were $\mathrm{H}$ ), the letter $\mathrm{O}$, or the other possible response (i.e., in this example, $S$ ), each trial was categorized as a member of the consistent, neutral, or conflicting conditions, respectively. The order of presentation of the different types of stimuli within a block was randomized. Subjects were instructed to name the local or the global shape aloud as fast as possible without making mistakes, and the time from the onset of each stimulus to that of its vocal response was recorded.

\section{Results}

The mean reaction times for correct responses are shown in Figure 3 as a function of stimulus sparsity (many or few local elements), local and global consistency (consistent, neutral, or conflicting), and attentional instruction (local or global). It should be mentioned that the patterns of results appeared to be similar for the $\mathrm{H}$ and $\mathrm{S}$ patterns, and so these data are combined throughout.

Analysis of variance showed that reaction times were faster for local $(556.2 \mathrm{msec})$ than for global attention $(621.4 \mathrm{msec}) \quad[\mathrm{F}(1,15)=13.96, \mathrm{p}<.01]$ and that the consistent $(560.2 \mathrm{msec})$, neutral $(580.8 \mathrm{msec})$, and conflicting $(625.5 \mathrm{msec})$ conditions differed in their values $[F(2,30)=36.95, p<.001]$, but that there was no main effect of sparsity $[F(1,15)=2.73]$. Importantly, there was a two-way interaction between sparsity and attentional instruction $[F(1,15)=63.44, p<.001]$. The mean reaction times were examined further, using Newman-Keuls technique (which was used in all the a posteriori tests to be reported). For many-element stimuli, global $(557.3 \mathrm{msec})$ was faster than local attention $(597.8 \mathrm{msec}) \quad(\mathrm{p}<.05)$. For few-element stimuli, in contrast, local $(514.8 \mathrm{msec})$ was faster than global attention $(685.5 \mathrm{msec})(\mathrm{p}<.01)$.

A three-way interaction among sparsity, attentional instruction, and consistency level $[\mathrm{F}(2,30)=18.52$, $\mathrm{p}<.001]$ was examined in a similar manner. First, the four different categories of the neutral condition were

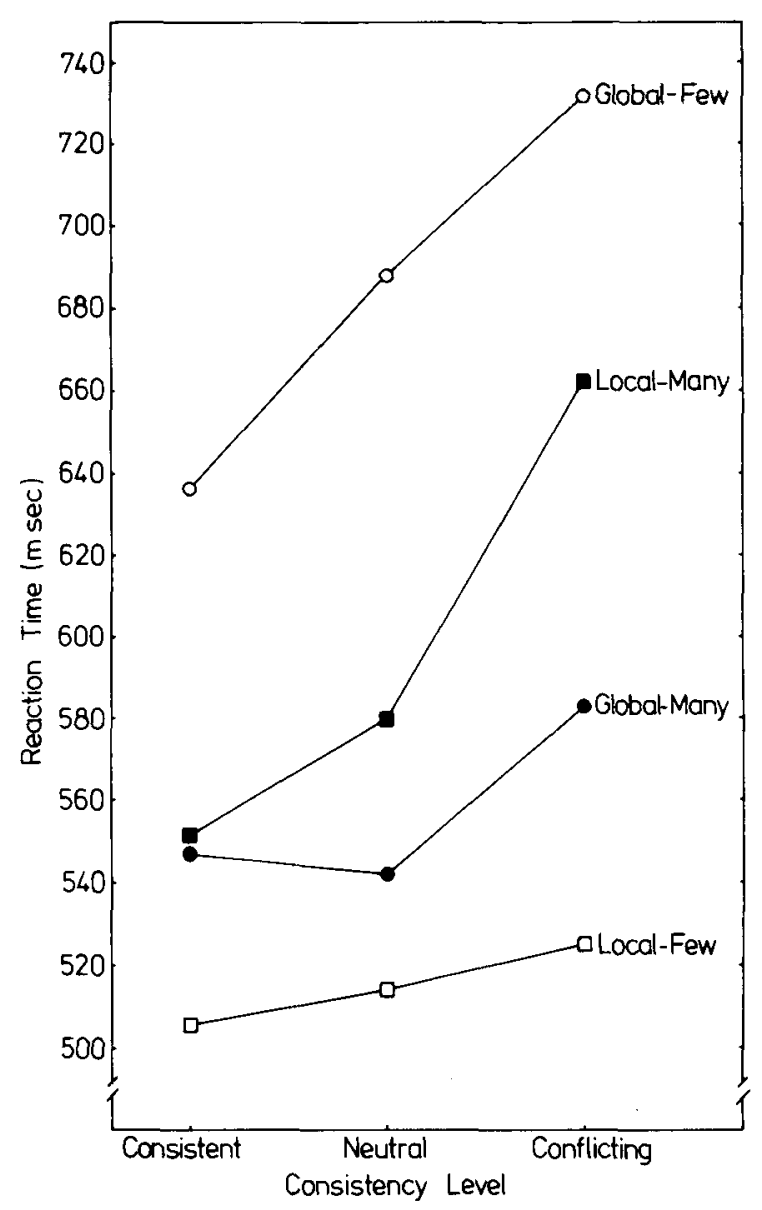

Figure 3. Latencies in Experiment 1 for reporting of local and of global aspects of many-element and of fewelement stimuli, as a function of the level of consistency of the secondary aspect.

compared. It was found that global attention was faster (by $37.5 \mathrm{msec}$ ) than local attention for many-element stimuli $(p<.05)$, whereas local attention was faster (by $174.1 \mathrm{msec}$ ) than global attention for few-element stimuli $(p<.01)$. Second, the six different categories using many-element stimuli were compared. It was found that for global attention the conflicting condition was slower than both the consistent condition (by $41.0 \mathrm{msec}$ ) and the neutral condition (by $35.9 \mathrm{msec}$ ) ( $p<.05)$, although the latter two did not differ significantly from each other; for local attention, the conflicting condition was slower (by $82.8 \mathrm{msec}$ ) than the neutral condition $(\mathrm{p}<.01)$, which was itself slower (by $27.8 \mathrm{msec})$ than the consistent condition $(p<.05)$. Third, the six different categories using few-element stimuli were compared. It was found, in contrast, that for global attention the conflicting condition was slower (by $43.8 \mathrm{msec})$ than the neutral condition $(\mathrm{p}<.01)$, which was itself slower (by $51.3 \mathrm{msec}$ ) than the consistent condition ( $p<.01)$; for local attention, there was no significant effect of consistency.

Accuracy of report in this experiment is displayed in Figure 4. The close similarity of this to Figure 3 means that the particular configuration of the latter cannot be 


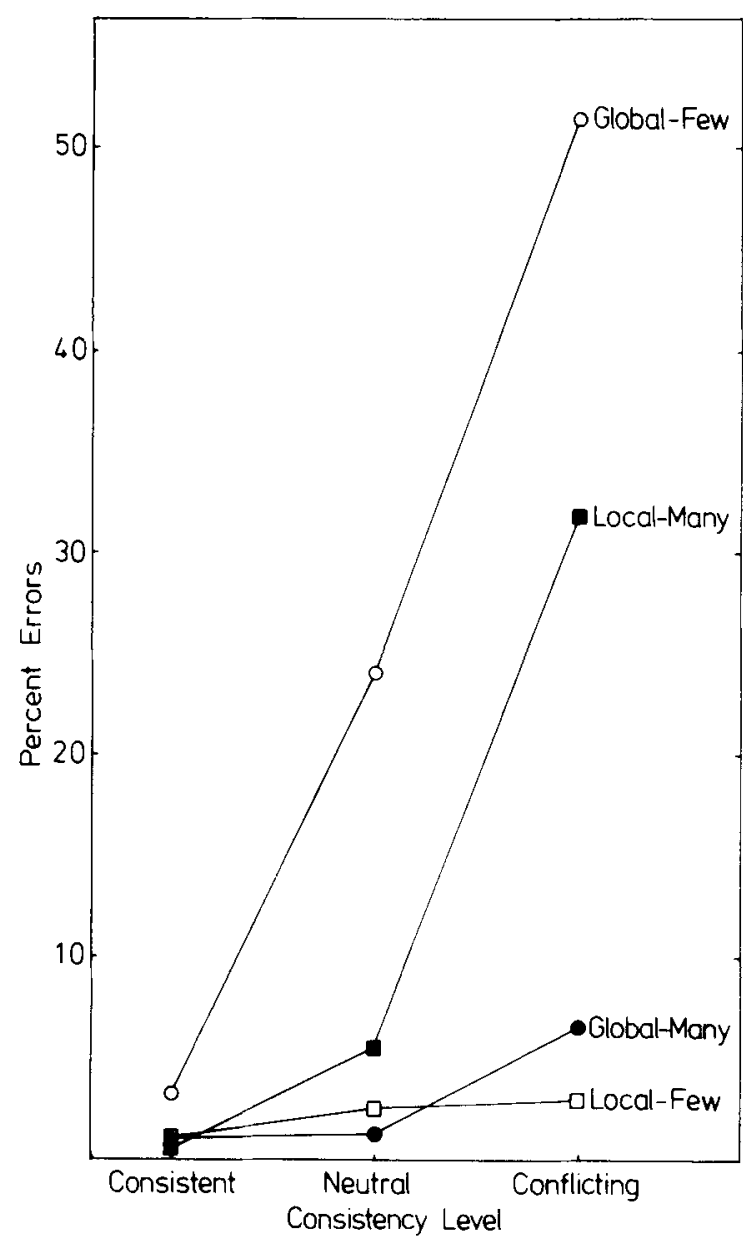

Figure 4. Errors in Experiment 1 in the reporting of local and of global aspects of manyelement and of fewelement stimuli, as a function of the level of consistency of the secondary aspect.

attributed to speed and accuracy tradeoff effects. An analysis of variance was carried out on the accuracy data, but care must be taken in the interpretation of its results because of potential ceiling effects, since accuracy was greater than $90 \%$ in all but one-fourth of the conditions. Accuracy was greater for local $(92.6 \%)$ than for global attention $(85.5 \%) \quad[\mathrm{F}(1,15)=21.32$, $\mathrm{p}<.001]$; consistent $(98.6 \%)$, neutral $(91.7 \%)$, and conflicting $(76.9 \%)$ conditions differed in accuracy $[F(2,30)=69.6, p<.001]$; and accuracy was greater for many-element $(92.2 \%)$ than for few-element stimuli $(85.9 \%)[F(1,15)=17.52, p<.001]$. As before, there was a two-way interaction between sparsity and attentional instruction $[\mathrm{F}(1,15)=71.84, \mathrm{p}<.001]$. For many-element stimuli, global $(97.0 \%)$ was more accurate than local attention $(87.4 \%)(\mathrm{p}<.01)$. For few-element stimuli, in contrast, local $(97.8 \%)$ was more accurate than global attention $(73.9 \%)(\mathrm{p}<.01)$.

A three-way interaction occurred between sparsity, attentional instruction, and consistency level $[F(2,30)=$ $52.90, \mathrm{p}<.001]$. In the neutral condition, global was numerically but not significantly more accurate (by $4.2 \%$ ) than local attention for many-element stimuli, while local was more accurate (by $21.4 \%$ ) than global attention for few-element stimuli $(p<.01)$. For the many-element stimuli, there was no significant effect of consistency for global attention; the conflicting condition was less accurate than the neutral (by 26.3\%) and consistent (by $31.3 \%$ ) conditions (which did not differ significantly from each other) $(p<.01)$ for local attention. For the few-element stimuli, the conflicting condition was less accurate (by 27.3\%) than the neutral condition $(\mathrm{p}<.01)$, which was itself less accurate (by $20.8 \%)$ than the consistent condition $(p<.01)$ for global attention; there was no significant effect of consistency for local attention.

\section{Discussion}

The latency and accuracy data reported here demonstrate that, contrary to the proposal of Navon (1977), global aspects are not invariably favored over local aspects in speed of processing. Depending upon conditions, either local or global aspects may be more favored. A similar general conclusion has been reached independently by McLean (1978). Both overall and for the neutral condition in isolation (in which response competition is eliminated), it was found that, although global processing was significantly faster than local processing for stimuli with many local elements, it was significantly slower than local processing for stimuli with few local elements. In conjunction with the race model (Cohen \& Martin, 1975; Martin, 1978a; Morton \& Chambers, 1973), the dependency of speed of local and global processing upon stimulus sparsity also accounts successfully for the observed effects of variation in the degree of consistency of local and global aspects. For stimuli with many local elements, global aspects are processed more rapidly than local ones, and hence the naming of local attributes suffers more from Strooplike interference than does the naming of global ones. The fact that there was nevertheless significant Strooplike interference in both directions resembles the results of Pomerantz and Sager (1975) and may be contrasted with the unidirectional effect found by Navon (1977, Experiment 3 ). The latter result is attributed by the race model to a smaller degree of overlap in local and global processing times. Similarly, for stimuli with few local elements, global aspects were found here to be processed more slowly than local ones, and hence their naming suffers more from Stroop-like interference than does that of local aspects.

An important aspect of this experiment was that the many-element and few-element stimuli both subtended exactly the same visual angle. Thus the present pattern of results cannot be attributed to some switch between foveal and peripheral attention, as described by Navon (1977, p. 380): "If the perceiver is close enough to the forest, he will probably see a tree rather than a forest. 
In this case, however, the tree is seen foveally, whereas everything else is seen peripherally." In practice, whether or not a global aspect is favored in processing can be manipulated independently of the visual angle that it subtends.

The present results are nevertheless consistent at the empirical level with those of Navon (1977) and of several other workers. The stimuli used by Navon (1977, Experiment 3) consisted of 6 by 7 local elements similar to the 5 by 7 many-element stimuli employed here, and they yielded similar global precedence results. It is somewhat puzzling only that Navon (1977) reported that his local and global elements were individually equally perceptible. However, the control conditions on which this conclusion was based differed in several respects from those of his Experiment 3: Presentation was in a fixed, rather than a variable, location, the local elements were isolated rather than grouped, and the global arrays were composed of a larger number of visual elements. Stirling and Coltheart (1977) found that the latency for naming the global attribute of a 5 by 5 stimulus was longer than that for a 5 by 7 one, which would be expected according to the present explanation due to the relative favoring of local processing in the former case; unfortunately, the naming of local attributes was not examined in this study. Finally, Pomerantz and Sager (1975) found that sorting stimulus cards on the basis of a global attribute suffered more interference from irrelevant local attributes for 3 by 3 stimuli than for 7 by 7 stimuli, again as would be expected on the present account.

Although the present experiment demonstrated several behavioral relationships between the sparsity of a stimulus's local elements and the relative favoring of global and of local processing, it did not investigate the occurrence of any phenomenal correlate. Thus, the next experiment was carried out to investigate whether the manipulation of stimulus sparsity also affects conscious visual experience in a similar manner.

\section{EXPERIMENT 2}

\section{Method}

Subjects. There were 10 new subjects, 5 female and 5 male. Other particulars were the same as in Experiment 1.

Stimuli and Apparatus. The stimuli and apparatus were the same as those of Experiment 1, exœpt that the stimulus pattern was positioned in the center of each card rather than in one of its quadrants.

Procedure. On each trial, the subject saw two patterns in succession that differed only in sparsity. The subject was instructed for each trial to "compare the pair of stimuli and decide which is the easier to see." Before each trial, the subject was instructed to attend to either the local or the global letter and was informed of its identity, which was either $\mathrm{H}$ or $\mathrm{S}$. As in Experiment 1, the unattended letter was $\mathrm{H}, \mathrm{S}$, or $\mathrm{O}$.

On each trial, an auditory signal wamed the subject to look at the central fixation point. It was followed $3 \mathrm{sec}$ later by the first stimulus, which appeared for $100 \mathrm{msec}$ and was followed immediately by a visual random noise mask for $1 \mathrm{sec}$. The fixation point then reappeared for a further $3 \mathrm{sec}$ and was followed by the second stimulus and then a mask, as before. The subject's spoken response was recorded by the experimenter. Each of the six stimuli with a global $H$ or $S$ and each of the six stimuli with a local $\mathrm{H}$ or $\mathrm{S}$ was used twice, once with the manyelement stimulus first and once with the fewelement stimulus first, in a randomized sequence of 24 trials per subject.

\section{Results}

For global attention, the many-element stimulus was judged easier to see than the few-element stimulus on $83.3 \%$ of the trials. The value was greater than $50 \%$ for 9 of the 10 subjects ( $p=.011$, by sign test). For local attention, the few-element stimulus was judged easier to see on $80.8 \%$ of the trials. The value was greater than $50 \%$ for 9 of the 10 subjects and equal for 1 subject ( $\mathrm{p}=.002$, by sign test).

\section{Discussion}

The results of this experiment demonstrate that the manipulation of stimulus sparsity affects whether local or global processing is favored when monitoring is at the level of consciousness in the same way as when it is at the purely behavioral level. Stimuli with many local elements are judged easier to process globally than those with few local elements, whereas for local processing the judgments are reversed. Thus, in this case the content of consciousness appears to reflect underlying processing in a veridical manner, although recent work has demonstrated that this need not be so (e.g., Allport, 1977; Schneider \& Shiffrin, 1977; Shiffrin \& Schneider, 1977).

Local and global visual processing may be further investigated by examining the manner in which the two types interact (if at all) with cooccurring auditory processing of related material. It is generally found that concurrent stimulation of a secondary modality by information consistent with that input to the primary modality facilitates processing of the latter in reaction times tasks (e.g., Bernstein, 1970; Bernstein \& Edelstein, 1971; Simon \& Craft, 1970). This intersensory facilitation may be attributed to the alerting or preparatory properties of the secondary stimulus (Bernstein, 1970; Nickerson, 1973) and perhaps to selective sensory processing (Seif \& Howard, 1975). Conversely, inconsistent secondary stimulation may interfere with primary processing. Thus in a study in which the primary task was to respond to a visual digit, Mynatt (1977) found that reaction time was facilitated when the auditory secondary stimulus was the same digit and was impaired when it was a different digit (both relative to the level for a random noise stimulus). In addition, similar results are obtained when the latency of the P300 event-related brain potential (see Price \& Smith, 1974) is measured (Squires, Donchin, Squires, \& Grossberg, 1977).

In a study directly relevant to the present issues, Navon (1977, Experiments 1 and 2) found that the discrimination of auditorily presented letters was slower when a visual display was presented concurrently (the maximum effect occurred in fact when the auditory discrimination was delayed by $40 \mathrm{msec}$ ). The magnitude of the effect depended on the nature of the visual stimuli's global attributes but not of their local ones. 
Navon proposed that the effect arose because, in the absence of instructions to focus attention, global, but not local, attributes invariably receive processing. The results reported here, however, suggest that the effect arose from faster global than local processing of manyelement stimuli, an asymmetry that might be reversed for few-element stimuli.

\section{EXPERIMENT 3}

This experiment investigated the effects on an auditory discrimination task of the cooccurrence of either a few-element or a many-element stimulus at which subjects were instructed to look.

\section{Method}

Subjects. There were eight new subjects, four female and four male. Other particulars were the same as in Experiments 1 and 2 .

Stimuli and Apparatus. The visual stimuli and apparatus were the same as those of Experiment 2, with the addition of two stimuli displaying the previously unused patterns shown in Figures 1 and 2 (i.e., those with both local and global $O$ shape).

The auditory stimuli consisted of the clearly audible spoken names of the letters $\mathrm{H}$ and S (viz., "ach" and "es"). Identical copies of the two letter sounds were presented in a random sequence using a tape recorder. Preceding each letter sound, a tone occurred on an additional tape channel (not linked to the subject's headphones), which caused the tachistoscopic display to commence $40 \mathrm{msec}$ prior to the onset of the letter sound

Procedure. On each trial, an auditory signal warned the subject to look at the central fixation point in the tachistoscope. It was followed $3 \mathrm{sec}$ later by the visual stimulus, which appeared for $100 \mathrm{msec}$ and was followed immediately by a visual random noise mask for $1 \mathrm{sec}$. On 1 trial in 10 (selected at random), the visual stimulus was replaced by a blank white card of the type constituting the backgrounds in the visual letter stimuli; this blank stimulus accompanied an auditory $H$ and an auditory $S$ once each in each successive set of 20 trials. The subjects' task was in each case to report aloud as fast as possible whether they heard an $\mathrm{H}$ or an $\mathrm{S}$, while looking concurrently at the visual display. The time from the onset of the auditory stimulus to that of the response was recorded on each trial.

There were 240 experimental trials, with 20 preceding practice trials. The experimental trials were divided into four equal blocks. Two blocks employed visual stimuli with many local elements, and two employed stimuli with few elements. The order of presentation of blocks was counterbalanced over subjects.

\section{Results}

The mean reaction times for correct auditory discriminations are shown in Table 1 as a function of the sparsity of the accompanying visual stimuli and as a function of the levels of consistency with the auditory stimuli of the local and global visual attributes. The error rate was less than $1 \%$ in all conditions.

Analysis of variance did not indicate any significant main effects or interactions in the data summarized in Table 1. An additional analysis demonstrated that the mean reaction times for trials with blank stimuli also did not differ from those shown in Table 1. For few-element stimuli, the blank stimulus value was $400.9 \mathrm{msec}$; the mean otherwise was $396.3 \mathrm{msec}$, with $95 \%$ confidence interval $=5.3 \mathrm{msec}$. For many-element stimuli, the corresponding data were $403.2 \mathrm{msec}$ and $401.4 \mathrm{msec}$, with $95 \%$ confidence interval $=5.9 \mathrm{msec}$.

\section{Discussion}

The presence of a secondary visual stimulus did not affect performance on the primary auditory discrimination task in this experiment. Although this result is perhaps surprising, one possible explanation lies in the fact that the subject did not have to respond to the visual stimulus in this experiment, which is different from the corresponding experiment of Navon (1977). Evidence exists that the making of a response to the secondary stimulus in such a situation is an important determiner of the resulting level of interference (Egeth, 1977; Massaro \& Wamer, 1977; Tulving \& Lindsay, 1967).

Thus, a new experiment was carried out that resembled Experiment 3, except that the subject had to identify the visual stimulus at the end of each trial. In addition, Experiment 3 differed from that of Navon (1977) in having the visual stimulus followed by a random noise mask that prevented prolonged processing from the sensory image (see Turvey, 1973). In Experiment 4, this mask was omitted.

\section{EXPERIMENT 4}

\section{Method}

Subjects. There were 16 new subjects, 8 male and 8 female. Other particulars were the same as in Experiments 1, 2, and 3.

Stimuli and Apparatus. Stimuli and apparatus were the same as those of Experiment 3.

Procedure. The procedure was the same as that of Experiment 3 except in three respects. First, the visual random noise mask after each visual stimulus was replaced by a blank white field. Second, the subjects were instructed that, after reporting the auditory stimulus, they were to describe, if possible, the visual stimulus, although this was of only secondary importance. Third, the blank trials were omitted, resulting in 216 experimental trials (four blocks of 54 each).

Table 1

Auditory Discrimination Latencies in Experiment 3 for Different Types of Accompanying Visual Stimuli

\begin{tabular}{|c|c|c|c|c|c|c|}
\hline \multirow[b]{3}{*}{ Local Aspect } & \multicolumn{6}{|c|}{ Global Aspect } \\
\hline & \multicolumn{3}{|c|}{ Few-Element Stimuli } & \multicolumn{3}{|c|}{ Many-Element Stimuli } \\
\hline & Consistent & Neutral & Conflicting & Consistent & Neutral & Conflicting \\
\hline Consistent & 394.00 & 391.50 & 394.71 & 406.67 & 404.53 & 398.50 \\
\hline Neutral & 393.25 & 407.34 & 388.68 & 401.59 & 415.06 & 390.23 \\
\hline Conflicting & 408.06 & 397.86 & 391.25 & 393.93 & 395.38 & 406.37 \\
\hline
\end{tabular}




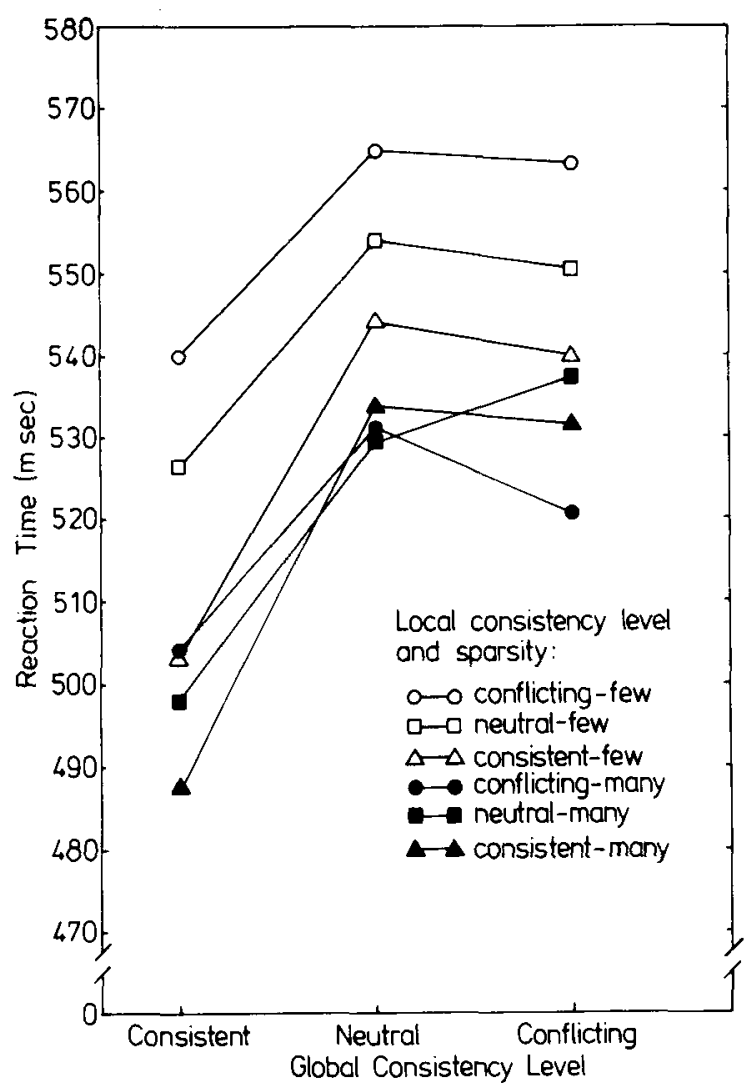

Figure 5. Auditory discrimination latencies in Experiment 4 as a function of the sparsity of accompanying visual stimuli and of the levels of consistency of their local and global aspects.

\section{Results}

The mean reaction times for correct auditory discriminations are shown in Figure 5 as a function of the sparsity of the accompanying visual stimuli and as a function of the levels of consistency with the auditory stimuli of the local and global visual attributes. The error rate was less then $1 \%$ in all conditions.

Analysis of variance showed that reaction times were faster for many-element accompanying visual stimuli $(519.4 \mathrm{msec})$ than for few-element stimuli $(542.9 \mathrm{msec})$ $[F(1,15)=10.72, p<.01]$. They differed also for the globally consistent $(509.8 \mathrm{msec})$, globally neutral $(543.1 \mathrm{msec})$, and globally conflicting $(540.5 \mathrm{msec})$ conditions $[F(2,30)=8.25, p<.01]$ and for the locally consistent $(523.4 \mathrm{msec})$, locally neutral $(532.7 \mathrm{msec})$, and locally conflicting $(537.3 \mathrm{msec})$ conditions $[F(2,30)=3.44, p<.05]$. For the few-element stimuli, there was a significant difference between consistent $(529.1 \mathrm{msec})$ and conflicting $(556.1 \mathrm{msec})$ stimuli $(\mathrm{p}<.05)$, with neutral stimuli intermediate $(543.7 \mathrm{msec})$. The many-element stimuli values for the consistent, neutral, and conflicting levels $(517.7,521.7$, and $518.6 \mathrm{msec}$, respectively), on the other hand, did not differ significantly. No other interactions reached significance.

\section{Discussion}

In this experiment, the effect of visual stimulation on concurrent auditory discrimination was reliably detected. The results again appeared in conflict with the global precedence hypothesis, since there was an effect not only of the level of consistency with the auditory stimulus of the global attributes, but also of that of the local attributes. The speed of processing model, on the other hand, correctly predicts a significant effect of the local level of consistency for few-element, but not for many-element, stimuli. Further, a significant effect of the global level of consistency for manyelement stimuli is correctly anticipated. The absence of an interaction between global consistency and sparsity was not expected, however. One admittedly speculative possibility is that processing of the global attribute of few-element stimuli was enhanced (presumably at some cost to local processing) by involuntary defocusing while the concurrent auditory discrimination was being carried out. Consistent with this is the finding that detailed visual processing may be impaired by arousing circumstances such as auditory noise (Kahneman, 1973, p. 38).

\section{GENERAL DISCUSSION}

Many visual scenes have aspects that can be categorized as either local or global. It has recently been proposed that global aspects are always processed before local ones (e.g., Broadbent, 1977; Navon, 1977). The experiments reported here demonstrate, however, that global precedence is not a universal phenomenon. These experiments used as visual stimuli arrays of small letters (local aspect), all of the same type, which together constituted a large letter (global aspect). Depending on the experimental condition, the two types of letter could be conflicting, neutral, or consistent with respect to each other (and also with respect to a possible further auditory stimulus letter). The results appeared to be satisfactorily accounted for by consideration of the effects of variation in the relative speeds of global and local processing as a function of stimulus sparsity. It was found that for stimuli with many local elements, global discrimination latencies were indeed faster than local ones; for stimuli with few local elements, however, the result was reversed (see neutral conditions of Experiment 1). It is of interest that phenomenal judgments were in agreement with behavioral methods of assessment, in that perception of global aspects was found easier for manyelement than for few-element stimuli, whereas for few-element stimuli, the result was reversed (Experiment 2).

Since the occurrence of Stroop-like interference is sensitive to the relative times of processing of its different constituents (Murray, Mastronardi, \& Duncan, 1971), it was used as a further index of relative speeds of processing. It was assumed that information from two different sources is processed in parallel until a limited-capacity bottleneck is encountered (see Martin, 1977; Treisman, 1969; Treisman \& Davies, 1973). The extent to which irrelevant information causes 
interference at that point is assumed to depend upon how fast that information was processed previously (e.g., Cohen \& Martin, 1975; Martin, 1978a; Morton \& Chambers, 1973). Thus, on the basis of the results previously discussed, it would be expected that maximum Stroop-like interference should derive from the global aspects of many-element stimuli and from the local aspects of few-element stimuli. This pattern of interference was indeed observed both for purely visual stimuli (Experiment 1) and for auditory discrimination (Experiment 4), although in the latter case global aspects of few-element stimuli also gave rise to significant interference.

The present results provide substantial evidence that stimulus sparsity is a powerful determinant of the relative ease of processing global and local aspects of stimuli. It is thus appropriate to consider the concept of sparsity itself further. In normal usage the word's connotation concerns the number of events that may be observed in a unit area, and it thus appears an appropriate term for referring to the factor along which the stimuli of Figures 1 and 2 differ. It must be recognized, however, that several different metrics may be proposed for representing the difference between the two sets of stimuli. A priori, the three most important are perhaps the numerical ratio of local to global elements, the average distance between local elements, and the ratio of the lengths of continuous contour of local to global elements. The last of these is particularly important, since it would be closely dependent upon the products of spatial frequency analysis (e.g., Campbell, 1974; Ginzburg, 1976), which has previously been suggested to underlie differences between local and global processing (Kinchla \& Wolf, 1979). For the present, however, further analysis of the precise role of sparsity in local and global processing must await additional empirical investigation.

\section{REFERENCE NOTE}

1. Norman, D. A., \& Bobrow, D. A. Descriptions: A basis for memory acquisition and retrieval (Tech. Rep. 74). San Diego: University of California, Center for Human Information Processing, Department of Psychology, November 1977.

\section{REFERENCES}

AlLPoRT, D. A. On knowing the meaning of words we are unable to report: The effects of visual masking. In S. Dornic (Ed.), Attention and performance VI. New York: Academic Press, 1977.

Bernstein, 1. H. Can we see and hear at the same time? Acta Psychologica, 1970, 33, 21-35.

Bernstein, I. H., \& Edelstein, A. Effects of some variation in auditory input upon visual choice reaction time. Journal of Experimental Psychology, 1971, 87, 241-247.

Bouma, H. Visual recognition of isolated lower-case letters. Vision Research, 1971, 11, 459-474.

Broadbent, D. E. The hidden preattentive process. American Psychologist, 1977, 32, 109-118.

Broadbent, D. E., \& Broadbent, M. H. P. Priming and the passive/active model of word recognition. In R. S. Nickerson
(Ed.), Attention and performance VIII. Hillsdale, N.J: Erlbaum, in press.

CAM PBELL, F. W. The transmission of spatial information through the visual system. In F. O. Schmitt \& F. G. Worden (Eds.), The neurosciences third study program. Cambridge, Mass: M.I.T. Press, 1974.

Cohen, G., \& Martin, M. Hemisphere differences in an auditory Stroop test. Perception \& Psychophysics, 1975, 17, 79-83.

EgETH, H. Attention and preattention. In G. H. Bower (Ed.), The psychology of learning and motivation (Vol. 7). New York: Academic Press, 1977.

Eisenstadt, M., \& Kareev, Y. Aspects of human problem solving: The use of internal representations. In D. A. Norman, D. E. Rumelhart, \& the LNR Research Group (Eds.), Explorations in cognition. San Francisco: Freeman, 1975.

Eriksen, C. W., \& Schultz, D. W. Temporal factors in visual information processing: A tutorial review. In J. Requin (Ed.), Attention and performance VII. New York: Academic Press, 1978.

Estes, W. K. The locus of inferential and perceptual processes in letter identification. Journal of Experimental Psychology: General, 1975, 104, 122-145.

Fox, J. Continuity, concealment and visual attention. In G. Underwood (Ed.), Strategies of information processing. London: Academic Press, 1978.

Gibson, E. J. Principles of perceptual learning and development. New York: Appleton, 1969.

GinzBurg, A. The perception of visual form: A two-dimensional filter analysis. In V. D. Gleger (Ed.), Proceedings of the fourth symposium on sensory system physiology (information processing in the visual system). Leningrad: Russian Academy of Sciences, 1976.

Johnston, J. C. A test of the sophisticated guessing theory of word perception. Cognitive Psychology, 1978, 10, 123-153.

Kahneman, D. Attention and effort. Englewood Cliffs, N.J: Prentice Hall, 1973.

Kinchla, R. A. Detecting target elements in multielement arrays: A confusability model. Perception \& Psychophysics, 1974, 15, 149-158.

Kinchla, R. A. The role of structural redundancy in the perception of visual targets. Perception \& Psychophysics, 1977, 22, 19-30.

KinChlA, R. A., \& WolfE, J. M. The order of visual processing: "Top-down," "bottom-up," or "'middle-out," Perception \& Psychophysics, 1979, 25, 225-231.

Krueger, L. Visual comparison in a redundant display. Cognitive Psychology, 1970, 1, 341-357.

LEVY, B. A. Reading: Speech and meaning processes. Journal of Verbal Learning and Verbal Behavior, 1977, 16, 623-638.

Lindsay, P. H., \& Norman, D. A. Human information processing: An introduction to psychology. New York: Academic Press, 1972.

Lockgead, G. R. Processing dimensional stimuli: A note. Psychological Review, 1972, 79, 410-419.

LUPKER, S. J. On the nature of perceptual information during letter perception. Perception \& Psychophysics, 1979, 25, 303-312.

Marslen-Wilson, W. D., \& Welsh, A. Processing interactions and lexical access during word recognition in continuous speech. Cognitive Psychology, 1978, 10, 29-63.

Martin, M. Reading while listening: A linear model of selective attention. Journal of Verbal Learning and Verbal Behavior, $1977,16,453-463$.

MARTIN, M. Retention of attended and unattended auditorily and visually presented material. Quarterly Journal of Experimental Psychology, 1978, 30, 187-200. (a)

Martin, M. Speech recoding in silent reading. Memory \& Cognition. 1978, 6, 108-114. (b)

Martin, M. Effect of list length on recall after dichotomous visual presentation. Acta Psychologica, in press.

Massaro, D. W. Perception of letters, words, and nonwords. Journal of Experimental Psychology, 1973, 100, 349-353.

Massaro, D. W., \& Warner, D. S. Dividing attention between 
auditory and visual perception. Perception \& Psychophysics, 1977, 21, 569-574.

McClelland, J. L., \& Johnston, J. C. The role of familiar units in perception of words and nonwords. Perception \& Psychophysics, 1977, 22, 249-261.

McLeAn, J. D. Perspectives on the forest and trees: The precedence of parts and wholes in visual processing. Unpublished doctoral dissertation, University of Oregon, 1978.

Monahan, J. S., \& Lockhead, G. R. Identification of integral stimuli. Journal of Experimental Psychology: General, 1977, 106, 94-110.

Morton, J., \& Chambers, S. M. Selective attention to words and colours. Quarterly Journal of Experimental Psychology, 1973, 25, 387-397.

Murray, D. J., Mastronardi, J., \& Duncan, S. Selective attention to "physical" vs. "verbal" aspects of colored words. Psychonomic Science, 1972, 26, 305-307.

MyNatT, B. T. Reaction times in a bisensory task: Implications for attention and speech perception. Journal of Experimental Psychology: Human Perception and Performance, 1977, 3, 316-324.

Navon, D. Forest before trees: The precedence of global features in visual perception. Cognitive Psychology, 1977, 9, 353-383. NeISSER, U. Cognition and reality. San Francisco: Freeman, 1976.

Nickerson, R. S. Intersensory facilitation of reaction times: Energy summation or preparation enhancement? Psychological Review, 1973, 80, 489-509.

Palmer, S. E. The effects of contextual scenes on the identification of objects. Memory \& Cognition, 1975, 3, 519-526. (a)

Palmer, S. E. Visual perception and world knowledge: Notes on a model of sensory-cognitive interaction. In D. A. Norman, D. E. Rumelhart, \& the LNR Research Group (Eds.), Explorations in cognition. San Francisco: Freeman, 1975. (b)

Pomerantz, J. R., \& Sager, L. C. Asymmetric integrality with dimensions of visual pattern. Perception \& Psychophysics, $1975,18,460-466$.

Price, R., \& Smith, D. D. B. The $P_{3(00)}$ wave of the averaged evoked potential: A bibliography. Physiological Psychology, 1974, 2, 387-391.

Purcell, D. G., Stanovich, K. E., \& Spector, A. Visual angle and the word superiority effect. Memory \& Cognition, 1978, 6, 3-8.

Reicher, G. M. Perceptual recognition as a function of the meaningfulness of stimulus material. Journal of Experimental Psychology, 1969, 81, 275-280.

Rumelhart, D. E., \& Siple, P. Process of recognizing tachistoscopically presented words. Psychological Review, 1974, 81, 99-118.
Schneider, W., \& Shiffrin, R. M. Controlled and automatic human information processing: I. Detection, search and attention. Psychological Review, 1977, 84, 1-66.

SEIF, T. F., \& How ARD, J. H., JR. Stimulus compatibility effects of an accessory visual stimulus on auditory sensitivity. Perception \& Psychophysics, 1975, 17, 504-510.

SElfridge, O. Pandemonium: A paradigm for learning. In Symposium on the mechanization of thought processes, London: H. M. Stationery Office, 1959.

Shiffrin, R. M., \& Schneider, W. Controlled and automatic human information processing: II. Perceptual learning, automatic attending, and a general theory. Psychological Review, $1977,84,127-190$.

Simon, J. R., \& Craft, J. L. Effect of an irrelevant auditory stimulus on visual choice reaction time. Journal of Experimental Psychology, 1970, 86, 272-274.

Squires, N. K., Donchin, E., Squires, K. C., \& Grossberg, S. Bisensory stimulation: Inferring decision-related processes from the P300 component. Journal of Experimental Psychology: Human Perception and Performance, 1977, 3, 299-315.

Stirling, N., \& Coltheart, M. Stroop interference in a letter naming task. Bulletin of the Psychonomic Society, 1977, 10, 31-34.

Stroop, J. R. Studies of interference in serial verbal reactions. Journal of Experimental Psychology, 1935, 18, 643-661.

Treisman, A. M. Strategies and models of selective attention. Psychological Review, 1969, 76, 282-299.

Treisman, A. M., \& Davies, A. Divided attention to ear and eye. In S. Kornblum (Ed.), Attention and performance IV. New York: Academic Press, 1973.

Treisman, A. M., \& Gelade, G. A feature-integration theory of attention. Cognitive Psychology, in press.

Treisman, A. M., Sykes, M., \& Gelade, G. Selective attention and stimulus integration. In S. Dornic (Ed.), Attention and performance VI. Hillsdale, N.J: Erlbaum, 1977.

Tulving, E., \& Lindsay, P. H. Identification of simultaneously presented simple visual and auditory stimuli. Acta Psychologica, 1967, 27, 101-109.

Turvey, M. T. On peripheral and central processes in vision: Inferences from an information-processing analysis of masking with patterned stimuli. Psychological Review, 1973, 80, $1-52$.

Wertheimer, W. Gestalt theory. Social Research, 1944, 11, 78-99.

WheEler, D. D. Processes in word recognition. Cognitive Psychology, 1970, 1, 59-85.

(Received for publication April 4, 1979; revision accepted September 6, 1979.) 